\title{
Pre-erythrocytic malaria vaccines: towards greater efficacy
}

\author{
Adrian V. S. Hill \\ Abstract | The complex life cycle of the malaria parasite Plasmodium falciparum provides \\ many options for vaccine design. Several new types of vaccine are now being evaluated in \\ clinical trials. Recently, two vaccine candidates that target the pre-erythrocytic stages of the \\ malaria life cycle - a protein particle vaccine with a powerful adjuvant and a prime-boost \\ viral-vector vaccine - have entered Phase II clinical trials in the field and the first has shown \\ partial efficacy in preventing malarial disease in African children. This Review focuses on \\ the potential immunological basis for the encouraging partial protection induced by these \\ vaccines, and it considers ways for developing more effective malaria vaccines.
}

\section{Sporozoite}

The form of the malaria parasite that is inoculated by mosquitoes into mammalian hosts.

Sterile protection Protection that prevents infection. In the case of pre-erythrocytic vaccines, this is generally regarded as prevention of infection of the blood by any blood-stage parasites.
Centre for Clinical Vaccinology and Tropical Medicine, and the Wellcome Trust Centre for Human Genetics, University of Oxford, Roosevelt Drive, Oxford OX3 7BN, UK. e-mail: adrian.hill@well. ox.ac.uk

doi: $10.1038 /$ nri1 746 Published online 9 December 2005
In 2005, with the Report of the Commission for Africa and particular attention at the G8 summit, there has been a renewed focus on the challenges of speeding up economic development and improving health in Africa. Malaria has seldom been out of the news ${ }^{1}$, and reports from researchers in Africa on the increasing global prevalence of malaria are worrying ${ }^{2}$. Estimates of mortality caused by malaria are $\sim 1-2$ million per year, with most of this mortality occurring in young African children, who are therefore widely regarded as the most important target population for a new vaccine.

Underlying the media headlines, there has been significant progress, but the realities of malaria control through vaccination are sobering. Quantitative data are now available to describe the magnitudes of some types of immune response that are required to confer protection against infection with Plasmodium Spp. or malarial disease ${ }^{3}$, but achieving these levels of immune response by vaccination has been difficult and maintaining them will probably be harder still. Many approaches to vaccine development are available but remain untested in the clinic. Vaccines, if they are to be implemented, will need to prove their worth against other control means, both new and established. These include bed nets that are impregnated with mosquito repellant, intermittent presumptive treatment with anti-malarial drugs, such as sulphadoxine-pyrimethamine ${ }^{4}$, and general economic development.

Nonetheless, the past year has been an exciting one for malaria vaccine development, with more candidate vaccines now in clinical development than ever before ${ }^{5}$. A trial in Mozambique has shown the first compelling evidence of some efficacy against disease in children, with a protein-plus-adjuvant approach originally designed to elicit immunity against sporozoites ${ }^{6}$. Vaccines targeted to the liver stage of the malaria parasite life cycle have also made progress, with repeatable efficacy being provided by prime-boost approaches ${ }^{3}$. Several of these advances have implications for vaccine development in general, beyond malaria: adjuvants, vectors and technologies that were initially tested for immunogenicity and efficacy in malaria now have applications for other diseases. For example, the adjuvant AS02A (discussed later) is being tested in new vaccine candidates for tuberculosis and HIV, and prime-boost vaccination with poxvirus boosting is a leading approach for new vaccines against both these diseases ${ }^{7}$. Malaria research has also provided the first evidence that a subunit vaccine can induce sterile protection through cell-mediated immunity in the absence of antibody induction ${ }^{3}$; new T-cell immunoassays are providing tantalizing clues to the effector mechanisms that are required for this protection $^{8-10}$.

Malaria vaccine development has progressed beyond the point at which a Review of this length could reasonably cover all the approaches. Several recent reviews focus on various aspects of this field ${ }^{11-14}$, including cellular immunity to blood-stage malaria ${ }^{15}$, the longrunning vaccine development programme at the Walter Reed Army Institute of Research, Maryland, USA ${ }^{16}$ and innate immunity to malaria ${ }^{17}$. Here, I focus on the two approaches that have shown consistent, albeit partial, efficacy in clinial trials. Both of these are preerythrocytic vaccines that, by definition, target either the sporozoite stage that is inoculated by the infectious mosquito, or the liver stage that immediately 


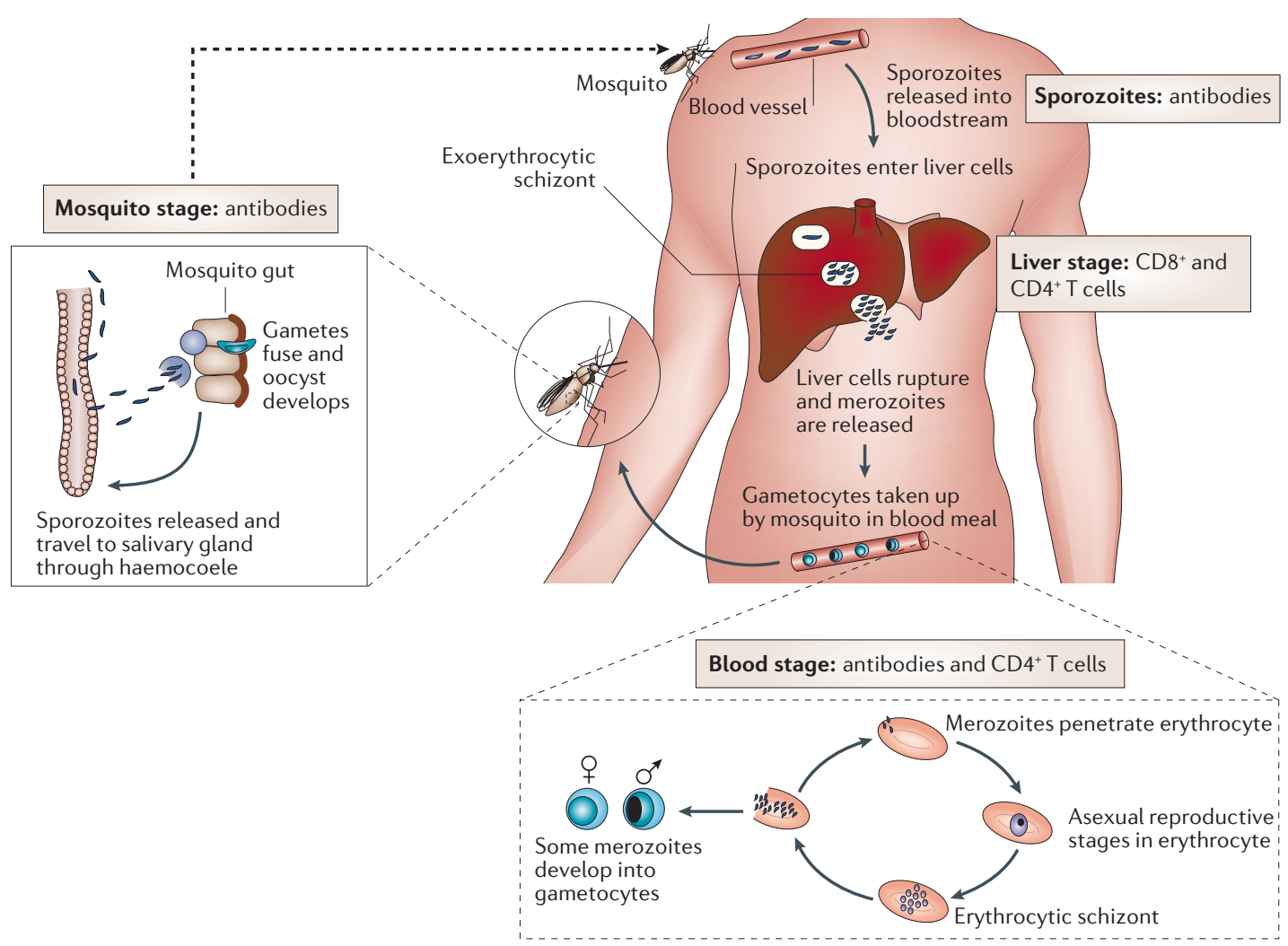

Figure 1 | The Plasmodium falciparum malaria life cycle. The mosquito injects sporozoites into the host, which are carried through the blood to the liver, where they invade hepatocytes and undergo a process of asexual (mitotic) replication to give rise to an exoerythrocytic schizont. Up to this point, the infection is non-pathogenic and clinically silent. After about seven days, the liver schizonts rupture to release many thousands of merozoites into the blood. Each merozoite invades an erythrocyte and divides mitotically to form an erythrocytic schizont, containing up to 20 daughter merozoites. These merozoites can re-infect fresh erythrocytes, giving rise to a cyclical blood-stage infection with a periodicity of 48-72 hours, depending on the Plasmodium species. As-yet-unknown factors trigger a subset of developing merozoites to differentiate into male and female gametocytes, which, when taken up by a feeding mosquito, give rise to extracellular gametes. In the mosquito mid-gut, the gametes fuse to form a motile zygote (ookinete), which penetrates the mid-gut wall and forms an oocyst, within which meiosis takes place and haploid sporozoites develop. The immune responses known to be protective at each main stage of the life cycle are shown.

follows (FIG. 1). Both of these are clinically silent stages of infection, and clearing of parasites or greatly reducing the parasite burden at these stages could markedly attenuate the disease burden in endemic areas. I review what these programmes have taught us about the challenging road ahead to deployable malaria vaccines that will prevent morbidity and mortality in African children.

\section{Rationale for malaria vaccine development}

The feasibility of malaria vaccination is supported by several observations. Epidemiological data and mathematical models indicate that beneficial levels of immunity to malaria are acquired with age, so that relatively few adults die of malaria in endemic regions ${ }^{18}$. In the 1970s, it was shown that humans, like many animals, could be immunized with irradiated sporozoites (BOX 1), implying that immunity against the pre-erythrocytic malarial stages alone could engender sterile protection lasting many months $s^{19,20}$. Many epidemiological studies have sought correlations between specific immune responses and reduced malarial incidence. Although several positive results have been found, there seems to be significant variation between studies and no overriding effects. Some of the most marked associations have been with immune responses to the main highly variable protein on the surface of infected erythrocytes, $P$. falciparum erythrocyte membrane protein $1(\mathrm{EMP} 1)^{21,22}$, which is a very difficult target for immunization because of its high rates of antigenic switching and considerable diversity. Overall, these studies indicate that natural immunity to malaria consists of a complex mixture of diverse immune responses, some of probably no protective value and some potentially counter-protective, such as pro-inflammatory responses that have been implicated in the pathology of cerebral malaria ${ }^{23}$. This indicates that subunit vaccines that include one or just a few antigens might need to evoke immune responses that are substantially greater than those generated by years of natural exposure to P. falciparum, to afford worthwhile protection.

The completion, in 2002, of sequencing the genome of P. falciparum - the causative agent of the great majority of fatal malaria cases - provided many insights into the scale of the challenge ${ }^{24}$. About 5,300 apparent 


\section{Box 1 | Irradiated sporozoite immunization}

The discouraging results with the use of first-generation DNA vaccines ${ }^{67,75,114}$, which had been advocated as a solution to malaria vaccination ${ }^{115}$ led, curiously to renewed interest in the possibility of whole-parasite vaccination with sporozoites ${ }^{116}$. Irradiated sporozoite immunization is highly effective for the protection of humans as well as animals, although protection that lasts beyond a year remains to be shown in humans. A biotechnology company, Sanaria Inc., Maryland, USA, has been established to develop irradiated sporozoite vaccines and aims to convert the current protocol for whole-parasite vaccination, which requires 1,000 or so mosquito bites, into a much more practical parenteral immunization regime with cryopreserved parasites ${ }^{116}$. Large numbers of sporozoites will need to be safe for administration after purification from mosquito salivary glands, an effective administration route other than intravenous inoculation will be required and, perhaps most challenging, a new effective means of sporozoite cryopreservation that does not kill them will be needed. The use of attenuated microorganisms as vaccines has a distinguished history, such as their use for vaccination against polio, tuberculosis and measles, but in malaria its future is uncertain. The discovery of the novel malaria parasite genes uis 3 and uis 4 , which can be deleted to render parasites unviable beyond the liver stage ${ }^{28,29}$, has been seen by some as relevant to sporozoite vaccination but, although removing the need for sporozoite irradiation, it leaves the main technical challenges of large-scale sporozoite growth, purification, cryopreservation and delivery route unchanged.

coding sequences were identified, many of completely unknown function. For a field that is already struggling with about 50 putative vaccine candidates, it was unclear whether the identification of thousands more candidate antigens would be helpful or otherwise. However, several advances from the genome and the related proteome project ${ }^{25}$ are already evident ${ }^{25,26}$. The stage-specificity of expression of many antigens in the malaria life cycle (FIG. 1) is being better defined, with several surprises - such as expression of the "bloodstage' antigens EMP1 and apical membrane antigen 1 (AMA1) by sporozoites. Searches for correlates of immunity to whole parasites, including irradiated sporozoites, have been greatly facilitated by the newly available sequences ${ }^{27}$. Finally, whole parasites with novel genes knocked out ${ }^{28,29}$, leading to their attenuation, are emerging as candidate vaccines, and transgenic technology is being used to test $P$. falciparum vaccine candidates in mice by transfection of the relevant gene into the genome of rodent parasites ${ }^{30}$.

\section{Anti-sporozoite vaccines}

$R T S, S$. The leading malaria vaccine candidate in terms of its stage in clinical development is named RTS,S/AS02A, which is a protein particle vaccine in a complex adjuvant $^{31}$. It is the result of many years of attempts to iteratively improve protective immunity to sporozoite challenge in a long-term collaborative programme between the Walter Reed Army Institute of Research and GlaxoSmithKline Biologicals, Rixensart, Belgium ${ }^{16}$. Initial studies in the late 1980s attempted to induce strong antibody responses to the main B-cell epitope in the (then recently sequenced) main sporozoite antigen, the circumsporozoite (CS) protein. The central repeat of CS protein that forms the B-cell epitope, which mainly consists of many copies of the tetrapeptide Asn-Ala-Asn-Pro in P. falciparum, is conserved between parasite variants and is the target of protective antibodies in rodent malaria. In these early challenge studies, individuals with the highest antibody titres were challenged and occasional volunteers were protected ${ }^{32,33}$. Formulation of the central repeat (the 'R' in RTS,S) with the entire carboxyl terminus of CS protein (containing known T-cell epitopes) into a fusion protein with the hepatitis B virus (HBV) surface (S) antigen (forming RTS) was intended to increase immunogenicity by generating particles and allowing $\mathrm{T}$-cell responses to target the C-terminal region of CS protein. Several viral antigens, such as the surface and core antigens of HBV, spontaneously form particles, and this has been found to enhance their uptake by antigen-presenting cells, and often their immunogenicity. However, to achieve particle formation in yeast, co-expression of an excess of non-hybrid HBV S-antigen was required (yielding RTS,S), presumably to overcome a lesser tendency of the recombinant protein to form particles.

An initial trial of RTS,S carried out in 1992 with alum plus 3-deacylated MPL (monophosphoryl lipid A) as the adjuvant, showed that two out of eight sporozoitechallenged individuals achieved sterile protection ${ }^{34}$. The next trial, reported in 1997 (REF. 31), compared three new adjuvants: AS02A, the oil-in-water emulsion AS03 and AS04, which contains the widely used alum adjuvant plus MPL. The results were remarkable. AS02A is a formulation of MPL, the triterpine saponin derivative QS21 (an extract from the plant Quillaja saponaria), and a proprietary oil-in-water emulsion (apparently identical to AS03). RTS,S formulated in the adjuvant AS02A protected six out of seven vaccinees who were challenged. Attention was therefore focused on the AS02A formulation, such that no further studies were undertaken of the adjuvant containing the oil-in-water emulsion alone (AS03), which protected two out of seven individuals. However, today this level of protection seems to be little different from the $33-41 \%$ protection that was observed in subsequent challenge trials with RTS,S/AS02A $\mathrm{A}^{35,36}$ (TABLE 1). The apparently higher protection (six out of seven vaccinees) observed in the first clinical trial ${ }^{31}$ might have been a chance finding, or could conceivably relate to the lower third dose of vaccine that was administered only in that trial because of reactogenicity concerns ${ }^{31}$. Although AS02A is probably better and more immunostimulatory for T helper $1\left(\mathrm{~T}_{\mathrm{H}} 1\right)$ cells than the other formulations, the efficacy of the MPL plus alum (AS04) and oil-in-water (AS03) formulations has a bearing on the key issue of the mechanism of protection (discussed later).

Subsequent field trials in The Gambia and Mozambique have been important. In 1998, a Phase IIb clinical trial in Gambian adult males assessed protection conferred by three doses of RTS,S/AS02A against microscopically detectable malarial infection, detected by weekly blood sampling over 16 weeks of a malaria 'season ${ }^{37}$. Although protective efficacy was $72 \%$ in the first 9 weeks of follow-up, it was zero thereafter, with some evidence of increased malaria incidence in the vaccinees during the next 7 weeks. Overall, efficacy against infection with any malaria strain was $34 \%$ (REF. 37), which is similar to the rates of sterile protection in the early challenge studies with homologous 
strain sporozoites ${ }^{31,34}$. Analysis of parasite genotypes in breakthrough infections of vaccinated individuals showed no evidence of an increased frequency of parasites with T-cell epitopes in the CS protein that were not present in the vaccine strain ${ }^{38}$, supporting a main role for antibodies specific for the conserved Asn-Ala-Asn-Pro repeat in the partial protection against malaria that was observed. This possibility is further supported by the strain specificity of responses to the main $\mathrm{CD} 4^{+} \mathrm{T}$-cell epitopes in the C-terminus of RTS, $\mathrm{S}^{39}$. A Phase IIb clinical trial of RTS,S/AS02A in 1-4-year-old children from Mozambique was reported in 2004 (REF. 6). In a 6 -month study of protection against clinical malaria, a $29.8 \%$ reduction in overall malaria incidence rate was observed: the primary trial endpoint. However, the clinical malaria incidence rates after 7 weeks of followup seemed to be similar in vaccinees and controls, indicating that efficacy might have waned rapidly, as in the Gambian trial ${ }^{37}$. Cumulative protection against episodes of malaria over 6 months was also significant at $27.4 \%$. In a parallel study of active surveillance of infection risk, there was a $45 \%$ reduction in the rate of acquisition of malarial infection ${ }^{37}$. Again, this effect was most evident in the first 2 months after vaccination.

This convincing, if partial, field efficacy against clinical malaria in children is a first for a malaria vaccine

\begin{tabular}{|c|c|c|c|c|c|c|}
\hline Vaccine candidate & Efficacy study & $\begin{array}{l}\text { Vaccination time } \\
\text { points (months) }\end{array}$ & Location & Number* & Outcome & References \\
\hline \multirow[t]{2}{*}{ RTS,S in AS02A } & Phase lla & $0,1,6$ & USA & 48 & $\begin{array}{l}41 \% \text { sterile protection, } \\
97 \% \text { reduction in } \mathrm{HPL}^{\mp}\end{array}$ & 31,35 \\
\hline & Phase Ilb (adults) & $0,1,5$ & The Gambia & 306 & $\begin{array}{l}34 \% \text { protection against } \\
\text { infection }\end{array}$ & 37 \\
\hline \multirow[t]{2}{*}{$\begin{array}{l}\text { FP9-MVA } \\
\text { ME-TRAP }\end{array}$} & Phase lla & 0 (FP9), 1 (FP9), 2 (MVA) & UK & 17 & $\begin{array}{l}40 \% \text { sterile protection", } \\
92 \% \text { reduction in } \mathrm{HPL}\end{array}$ & 3,73 \\
\hline & Phase Ilb (children) & $0,1,2$ & Kenya & 402 & In progress & $\begin{array}{l}\text { Unpublished } \\
\text { observations" }\end{array}$ \\
\hline \multirow[t]{2}{*}{$\begin{array}{l}\text { DNA-MVA } \\
\text { ME-TRAP }\end{array}$} & Phase lla & $\begin{array}{l}0 \text { (DNA), } 1 \text { (DNA), } \\
2 \text { (DNA), 3-4 (MVA), } \\
\text { 4-5 (MVA) }\end{array}$ & UK & 8 & $\begin{array}{l}0 \% \text { sterile protection, } \\
>80 \% \text { reduction in } \mathrm{HPL}\end{array}$ & 66 \\
\hline & Phase Ilb (adults) & $0,1,2$ & The Gambia & 372 & $\begin{array}{l}10 \% \text { (non-sterile) } \\
\text { protection against } \\
\text { infection }\end{array}$ & 71 \\
\hline $\begin{array}{l}\text { NYVAC encoding } \\
\text { seven antigens }\end{array}$ & Phase lla & $0,1,6$ & USA & 35 & $\begin{array}{l}3 \% \text { sterile protection, } \\
\text { significant delay to } \\
\text { patency }\end{array}$ & 64 \\
\hline $\begin{array}{l}\text { Plasmid DNA encoding } \\
\text { ME-TRAP }\end{array}$ & Phase lla & $0,1,2$ & UK & 5 & No protection & 66 \\
\hline $\begin{array}{l}\text { Plasmid DNA encoding } \\
\text { five antigens }{ }^{\star \star}\end{array}$ & Phase lla & $0,1,2$ & USA & 31 & No protection & 75 \\
\hline $\begin{array}{l}\text { ICC- } 1132 \text { in } \\
\text { Montanide ISA } 720\end{array}$ & Phase lla & 0 & UK & 11 & No protection & 42 \\
\hline \multicolumn{7}{|c|}{ 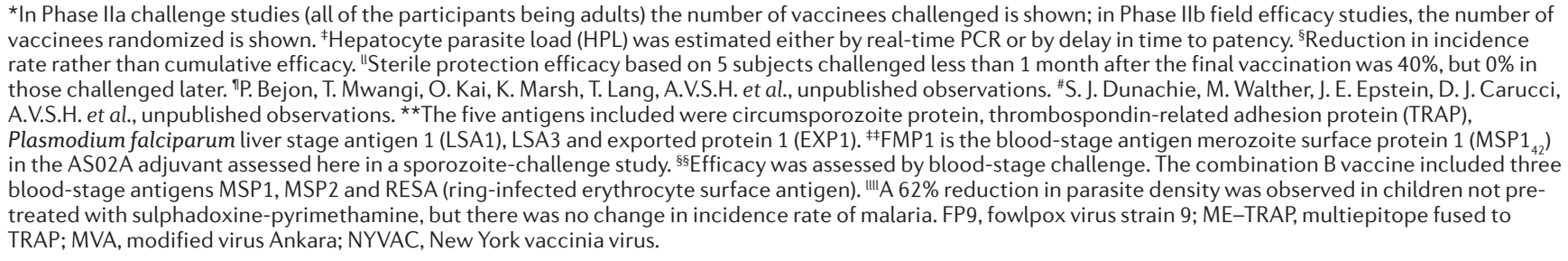 } \\
\hline
\end{tabular}


Cultured ELISPOT

A recently introduced modification of the ex vivo IFN $\gamma$ ELISPOT assay that involves a prolonged period of in vitro culture of lymphocytes before the IFN $\gamma$ ELISPOT assay. Typically, cells are cultured for 10-14 days with interleukin-2. This approach was originally used to enhance the sensitivity of the IFN $\gamma$ ELISPOT assay.

More recent evidence indicates that a different population

of central memory rather than effector T cells, might be measurable by this assay.

\section{Virosome}

A particulate vaccine formed of a liposome, in the membrane of which is added surface proteins of influenza virus, particularly haemagglutinin. Peptides from other sources such as Plasmodium falciparum can be incorporated by adding lipid tails, leading to exposure of the malaria peptide on the surface of the virosome vaccine. and provides a crucial proof-of-concept for the field. But several issues complicate assessment of the potential of this product. Foremost is the issue of duration of efficacy. This was indicated by the apparent rapid rate of loss of efficacy in sporozoite-challenge studies: at 6 months after vaccination, challenge of volunteers who were previously protected by RTS,S/AS02A in the month after vaccination showed a slight delay in time to parasitization but only one individual showed complete protection ${ }^{40}$. The magnitude of protection or efficacy level afforded (representing the proportion of people protected) is also suboptimal, but some have argued that as little as $30 \%$ protection might be adequate for vaccine deployment, although higher rates would obviously be desirable. A recent expert group report, entitled the Malaria Vaccine Technology Roadmap, has called for the production of a vaccine that is $50 \%$ effective for 2 years, to justify its deployment.

Other anti-sporozoite approaches. Other approaches to generating protective immunity against sporozoites have been clinically explored in the past year. The California-based biotechnology company Apovia Inc., in collaboration with New York University, have developed a recombinant HBV core particle that incorporates both the central repeat of the CS protein and two T-cell epitopes ${ }^{41}$. Although antibody immunogenicity to this vaccine construct in macaque monkeys with a Montanide ISA 720 oil-in-water adjuvant formulation was excellent ${ }^{41}$, reactogenicity issues prevented multi-dose administration in initial clinical trials. In a Phase I/IIa clinical trial with sporozoite challenge, antibody immunogenicity was modest and T-cell responses were minimal after a single dose of the HBV-based

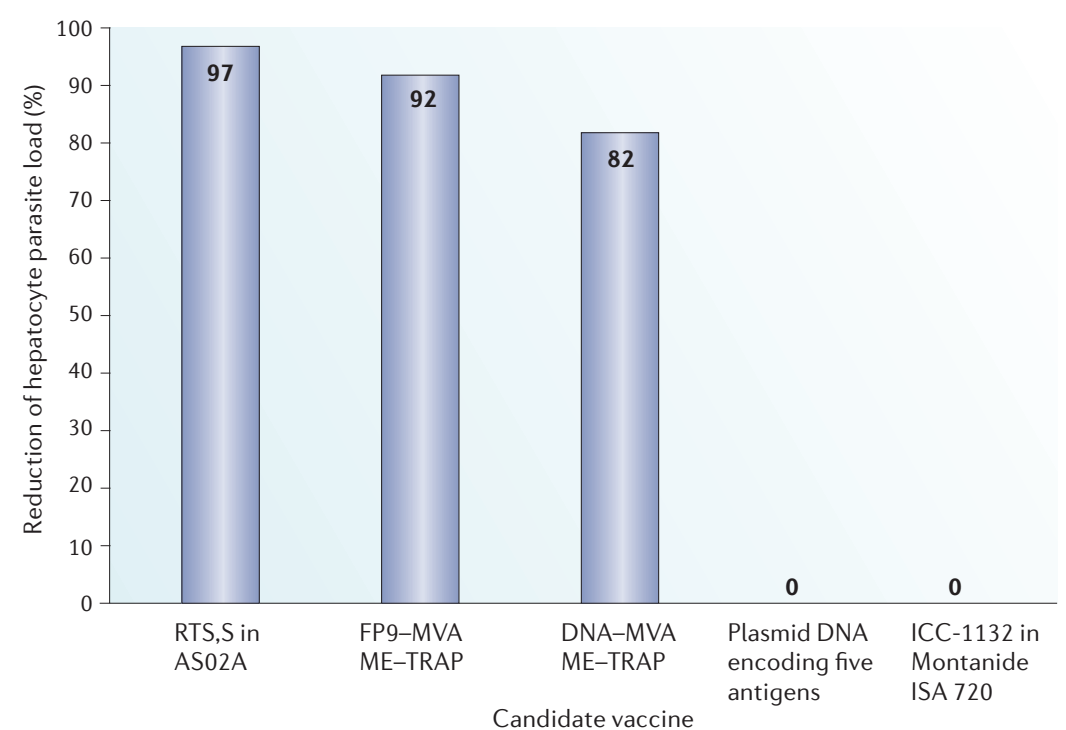

Figure 2 | Efficacy of various pre-erythrocytic vaccines against malaria. These vaccines were tested in Phase lla clinical trials of sporozoite challenge undertaken in recent years. They can be displayed as estimated reduction in liver-stage parasite load (measured as in REF. 73, or calculated from the mean delay in time to patent parasitaemia). Details of regimes and references are given in TABLE 1. Studies without a statistically significant protective effect are shown as $0 \%$ efficacy, although low-level protection may have been present without reaching significance in the sample studied. vaccine $^{42}$. There was no protection from infection (TABLE 1; FIG. 2). A Swiss company, Dictagene, in collaboration with the University of Lausanne, Switzerland has developed a vaccine consisting of a long CS proteinderived peptide also formulated in a Montanide ISA 720 adjuvant. A Phase I clinical trial showed some T-cell responses using a cultured interferon- $\gamma($ IFN $\gamma$ ) enzymelinked immunosorbent spot (cultured ELISPOT) assay and induction of antibodies ${ }^{43}$, and a sporozoite-challenge study has been undertaken.

A more recent product developed by the Swiss biotechnology company Pevion Biotech. Ltd. includes two $P$. falciparum lipopeptides formulated in virosomes. Virosomes are immunogenic liposomes that incorporate the influenza virus haemagglutinin protein to facilitate antigen processing, and lipid-tailed peptides with conformationally constrained cyclized B-cell peptide epitopes can be incorporated in the membrane $e^{44,45}$. Two licensed vaccines are based on virosomes. A Phase I clinical trial of a malaria vaccine using virosomes incorporating the Asn-Ala-Asn-Pro repeat from CS protein ${ }^{46}$ or part of domain III of the blood-stage protein AMA1 (REF. 47) showed good safety and antibody immunogenicity. No subsequent challenge study has been carried out. Overall, these studies highlight the difficulty of inducing the high levels of sporozoite-specific antibodies in humans that might be required for protection.

\section{Anti-liver-stage vaccines}

A different rationale for the design of a pre-erythrocytic vaccine is based on several types of evidence implicating T-cell immunity to the liver-stage parasite in protection (FIG. 1). Analysis of the strong protection that is inducible in mice, monkeys and humans by immunization with irradiated sporozoites (BOX 1) identified a main role for $\mathrm{T}$ cells in mediating protection, at least in mouse models, which can be analysed in detail ${ }^{48}$. Although $\mathrm{CD}^{+} \mathrm{T}$ cells are important in most host-parasite combinations in mice, $\mathrm{CD} 4^{+} \mathrm{T}$ cells might also be required for protection ${ }^{49}$. Results from adoptive-transfer experiments with T-cell clones specific for the CS protein or TRAP (thrombospondin-related adhesion protein, also known as SSP2) in mice ${ }^{50,51}$, and evidence of an HLA class I association with malaria resistance in Gambian children $^{52}$, have also encouraged pursuit of this cellmediated mechanism. Recently, correlations of specific $\mathrm{T}$-cell responses - mainly of the $\mathrm{CD} 4^{+} \mathrm{T}$-cell type - with resistance to malaria in humans, have supported protective roles for these $\mathrm{T}$-cell responses against various pre-erythrocytic antigens (discussed later).

An ability to undertake sporozoite-challenge studies in mice, macaques and humans (BOX 2) has allowed malaria to play a significant role in the general development of T-cell-inducing vaccines. Early studies showed $\mathrm{CD}^{+} \mathrm{T}$-cell induction by various types of vaccine, including lipopeptides, particles, plasmids and viral vectors ${ }^{53-56}$. However, the highest T-cell immunogenicity and efficacy has consistently been achieved with heterologous prime-boost approaches, in which a poxvirus vector is used as the boosting 


\section{Box $2 \mid$ Testing the efficacy of malaria vaccines}

Malaria is unusual in that the efficacy of vaccines can be tested in small numbers of individuals by deliberate infection with Plasmodium falciparum. These clinical 'challenge models' benefit from the ability of drugs to effect sterile clearance of fully characterized, drug-sensitive P. falciparum parasites.

Insectary-reared Anopheles stephensi mosquitoes are fed with blood containing gametocytes of the 3D7 strain of P. falciparum and five infectious bites (containing sporozoites) are administered to each vaccinee or non-vaccinated control. At least two endpoints are of interest: the proportion of vaccinated volunteers who are fully protected and the delay in time to infection, assessed by blood-film microscopy, in partly protected vaccinees. All non-vaccinated volunteers should develop malaria with a mean time to patency of about 11 days. A substantial reduction in the number of sporozoites or liver-stage parasites will delay the mean time to patency, providing a measure of partial efficacy. Assisted by monitoring of low parasite densities by real-time PCR, this can be converted into a percentage reduction in liver-stage parasite load.

Recently, there has been increasing interest in using a challenge model involving small numbers of blood-stage parasites to test blood-stage candidate vaccines. A smaller blood-stage inoculum, compared with sporozoite challenges, can lead to longer pre-patent periods, less interindividual variation and, therefore, probably more power to detect partial efficacy of blood-stage vaccine candidates.

Vaccines are generally field-tested first in adults in endemic areas, but because most adults have substantial immunity from natural exposure and develop malarial disease less often than children, this might be an insensitive means of testing partially effective vaccines. Children and infants, particularly in Africa, represent the most important target population for new vaccines and efficacy against clinical malaria can be measured in samples of a few hundred children. Two measures of efficacy are commonly used: a reduction in disease incidence rate and a reduction in overall cases per unit time. For vaccines with a short duration of efficacy, these numbers can differ significantly.

Views also differ on the importance of demonstrating efficacy against severe malarial disease prior to licensure. This would involve studies of many thousands of children, but has been encouraged by the hope that, for some vaccines, efficacy might be greater against severe malaria than uncomplicated malaria.

Heterologous prime-boost When a single application of a vaccine is insufficient, repeated immunizations are carried out using the same vaccine preparation (homologous prime-boost) or using different vaccine preparations

(heterologous prime-boost) to sequentially stimulate a better immune response.

\section{Ex vivo ELISPOT}

Ex vivo interferon- $\gamma$ enzyme linked immunosorbent spot assays are now widely used to measure antigen-specific effector T cells. Typically, splenocytes or peripheralblood mononuclear cells are incubated with the antigen for 18 hours and the release of cytokines, such as interferon- $\gamma$ by antigen-specific cells allows their enumeration by a modified enzyme-linked immunosorbent assay (ELISA) technique. agent ${ }^{57-61}$. In such regimes, two different vectors or vaccine-delivery systems are generally used, each encoding the same antigen. Part of the enhanced T-cell immunogenicity of such regimes simply relates to the avoidance of anti-vector immunity with the heterologous booster immunization. However, other factors probably contribute, including an ability of certain viruses to boost T-cell responses despite preexisting immunity to the encoded antigen that tends to impair the boosting capacity of other vaccine types. Plasmid DNA, avipox vectors, such as an attenuated strain of fowlpox virus (FP9), and adenovirus vectors have all been used as successful priming agents in mice, with the attenuated orthopoxvirus, modified virus Ankara (MVA), as the boosting vector. In macaques, boosting with the attenuated New York vaccinia virus (NYVAC) was more protective than boosting with an avipox vector in protecting against Plasmodium knowlesi sporozoite challenge ${ }^{62,63}$. When used as a single vector, NYVAC expressing 7 different $P$. falciparum antigens, fully protected 1 out of 32 sporozoite-challenged volunteers, but this vector has not been pursued further ${ }^{64}$.

In clinical trials, the most extensively studied T-cell antigen has been the sporozoite antigen TRAP fused to a multiepitope string of mainly $\mathrm{CD}^{+} \mathrm{T}$-cell epitopes from six pre-erythrocytic antigens ${ }^{65}$. Most T-cell responses induced by these vectors are specific for the TRAP component, with the smaller multiepitope string being less immunogenic ${ }^{66}$. This lesser immunogenicity of the multiepitope string might simply reflect its shorter size and presence of only a few $\mathrm{CD} 4^{+} \mathrm{T}$-cell epitopes, as the vaccination regimes used have induced mainly CD4 ${ }^{+}$T-cell immunogenicity.

As in an earlier study of plasmid DNA encoding CS protein $^{67}$, vaccination of humans with plasmid DNA encoding ME-TRAP showed modest immunogenicity ${ }^{66}$. Responses averaged less than 100 SFUs (spot forming units, each corresponding to one IFN $\gamma$-producing cell) per million peripheral-blood mononuclear cells (PBMCs) in ex vivo ELISPOT assays. However, boosting the plasmid DNA with an MVA vaccine vector encoding ME-TRAP amplified responses to more than 1,000 SFUs per million PBMCs and induced a significant delay in time to parasitaemia in sporozoite-challenge studies ${ }^{66}$, or, in one case, complete protection (S. J. Dunachie, M.Walther, J. E. Epstein, D. J. Carucci, A.V.S.H. et al., unpublished observations; TABLE 1). This regime was also safe and immunogenic in semi-immune African individuals ${ }^{68-70}$, but a Phase IIb clinical trial assessing time to infection in adult Gambians showed non-significant protection of $10.3 \%$ (REF. 71).

More recently, the vector FP9 (REF. 72) was found to be a more immunogenic and protective priming vector than plasmid DNA in mouse studies ${ }^{61}$ and has now been evaluated clinically. The FP9-MVA prime-boost regime induced higher $\mathrm{CD}^{+} \mathrm{T}$-cell responses than the DNA-MVA regime ${ }^{9}$ and led to sterile protection in some volunteers with a significant delay in time to parasitaemia in others ${ }^{3}$. Monitoring of low-level parasite densities by PCR of volunteer blood samples was used in these recent challenge studies, allowing the reduction in parasite burden in the liver at the end of the liver stage of infection to be estimated. FP9-MVA regimes induced a $92 \%$ reduction in parasite burden in the liver ${ }^{73}$ (FIG. 2), which is greater than that induced by DNA-MVA, but lower than that induced by the RTS,S/ AS02A vaccine. However, a single volunteer was successfully re-challenged and completely protected twice, at 6 and at 20 months after vaccination, without any booster vaccinations between these challenges ${ }^{3}$. On re-challenge, this volunteer had no residual effector T-cell responses but had persisting central memory $\mathrm{T}$ cells as measured in a cultured IFN $\gamma$ ELISPOT assay. As in all studies with CS protein and ME-TRAP vectored vaccines, antibody levels induced by this regime were low or absent and were not associated with protection. However, both ex vivo and cultured IFN $\gamma$ ELISPOT assays, which measure mainly effector and central memory T cells, respectively, showed association with protection ${ }^{3,74}$. The ME-TRAP vaccine that was delivered using an FP9-MVA regime has been found to be immunogenic in Gambian ${ }^{70}$ and Kenyan adults, and a Phase IIb efficacy trial in Kenyan children has been initiated to assess protection against febrile malaria, which is more common in children than in adults, who have high levels of 'anti-disease' immunity and can tolerate parasitaemia without symptoms 
(P. Bejon, T. Mwangi, O. Kai, K. Marsh, T. Lang and A.V.S.H., unpublished observations). This clinical endpoint of febrile malaria is similar to that used in the recent trial of RTS,S/AS02A in Mozambique ${ }^{6}$, which reflects a growing consensus on using measures of efficacy against disease rather than infection in field trials.

In an attempt to mimic more closely the broad T-cell responses induced by irradiated sporozoite vaccination (BOX 1), the US Naval Medical Research Center has evaluated a mixture of five DNA plasmids encoding different pre-erythrocytic antigens - with or without the gene encoding granulocyte/macrophage colonystimulating factor (GM-CSF) as an immunomodulator that is designed to enhance vaccine immunogenicity — in a Phase I/IIa clinical trial, but no efficacy against sporozoite challenge was observed ${ }^{12,75}$. Some volunteers who were vaccinated previously with plasmid DNA encoding the CS protein were then boosted with RTS,S/AS02A, and showed some evidence of broadening of the induced immune responses, but no subsequent challenge study was carried out ${ }^{76}$.

These studies have indicated that it is possible to substantially reduce parasite numbers in the liver in vaccinees, by using vectored vaccines. They have also identified the approximate magnitude of T-cell responses that are required to reduce parasite burden, at least as measured by ex vivo IFN $\gamma$ ELISPOT assays. Efforts to develop more immunogenic vectors and regimes for protective $\mathrm{T}$-cell induction continue and it is probable that some promising adenoviral vectors ${ }^{16,77,78}$ will soon be evaluated clinically, both alone and in heterologous prime-boost regimes.

\section{Correlates of pre-erythrocytic protection}

A key objective of many of the early stage pre-erythrocytic vaccine trials that have been undertaken over the past 20 years has been to assess immunogenicity and to try to correlate this with protection against sporozoite challenge. The availability of a safe, relatively standardized, sporozoite-challenge model provides researchers involved in malaria-vaccine development with an opportunity to search for immune correlates of protection, which is impossible in early stage studies of almost all other prophylactic vaccines. Identification of such an immune correlate is important for several reasons. It allows optimization of a particular immune response by adjusting the vaccine regime or dosage, and facilitates the testing of vaccine potency. It provides a measure to guide vaccination regime choice and estimate probable vaccine efficacy as vaccine development progresses to different target populations and age groups. Often, it has also allowed improvement of the vaccine, by alteration of the adjuvant or vector used to achieve better protection. Note that vaccine-induced immune correlates will probably differ from correlates in field studies of natural immunity, as the immune correlates in the field generally consist of a compendium of low-level responses to a multitude of antigens, whereas responses to a single antigen induced by a subunit vaccine need to be much stronger to be protective.
Animal models. Studies in mice of vaccine-induced protection against sporozoite challenge showed that antibodies specific for the central repeat of the CS protein were protective, at least at high titres ${ }^{79,80}$. However, induction of high-level antibody titres was found to depend on the presence of MHC-class-II-restricted T-cell epitopes in the immunogen, indicating one possible reason for inter-individual variation in immunogenicity ${ }^{81}$. By contrast, analyses of the mechanism of protection afforded by irradiated sporozoite immunization generally showed CD8 ${ }^{+} \mathrm{T}$-cell dependence ${ }^{48,49,79}$. $\mathrm{CD}^{+} \mathrm{T}$-cell clones derived from immunized mice could confer protection after adoptive transfer ${ }^{50,51}$. However, a detailed comparison of several mouse strains showed $\mathrm{CD} 4{ }^{+} \mathrm{T}$-cell dependence in some strains, together with variable requirements for natural killer (NK) cells, inducible nitric-oxide synthase (iNOS) and interleukin-12 (IL-12) (REF. 49), despite main roles for $\mathrm{CD}^{+} \mathrm{T}$ cells and IFN $\gamma$. The protective potential of $\mathrm{CD}^{+}$effector $\mathrm{T}$ cells was highlighted by the demonstration that a $\mathrm{CD} 4^{+} \mathrm{T}$-cell epitope could induce protection mediated by IFN $\gamma$-secreting T cells ${ }^{82}$. Another aspect of sporozoite-induced immunity is the apparent requirement for antigen persistence in the liver, to maintain protective immunity. This was demonstrated by the abrogation of protection in irradiated rats that were immunized with sporozoites by chemotherapy with anti-malarial drugs to remove liver parasites ${ }^{83}$. Protection has been proposed to be associated with the persistence of various populations of $\mathrm{CD} 8^{+} \mathrm{T}$ cells in the mouse liver ${ }^{84}$.

Natural immunity in humans. Correlates of protection with pre-erythrocytic immunity in field studies have been rare. In general, the levels of sporozoite-specific antibodies in people naturally exposed to malaria do not correlate with protection, probably because these naturally evoked levels are low and the responses are short-lived $^{85}$. However, some studies have indicated that antibodies specific for TRAP might correlate with protection in Mali ${ }^{86,87}$ and Kenya ${ }^{88}$. Recently, studies of T-cell responses to CS protein in Gambian individuals ${ }^{10}$ showed a repeatable protective correlation with (14-day) cultured IFN $\gamma$ ELISPOT responses to a highly conserved $\mathrm{CD}^{+}{ }^{+} \mathrm{T}$-cell epitope ${ }^{89}$ near the $\mathrm{C}$-terminus of the CS protein. These responses correlated with protection against both infection and disease, with substantial protection against disease. Ex vivo IFN $\gamma$ ELISPOT assays, however, showed no correlations. This supports growing evidence that central memory $\mathrm{T}$ cells ${ }^{90}$, as measured by cultured IFN $\gamma$ ELISPOT assays ${ }^{10,91,92}$, rather than effector $\mathrm{T}$ cells, as measured by ex vivo IFN $\gamma$ ELISPOT assays, could be of most protective value. This conserved $\mathrm{CD} 4^{+} \mathrm{T}$-cell epitope of the CS protein might be of value for inclusion in future vaccine constructs. Two smaller-scale epidemiological studies in Gabon ${ }^{93}$ and Kenya ${ }^{94}$ have also indicated that IFN $\gamma$ production in response to peptides derived from $P$. falciparum liver-stage antigen 1 (LSA1), measured in 5-day culture supernatants by enzyme-linked immunosorbent assay (ELISA), might correlate with protection. 


\begin{tabular}{|c|c|c|c|c|c|c|}
\hline \multirow[t]{2}{*}{ Type of vaccine } & \multirow[t]{2}{*}{ Insert } & \multirow[t]{2}{*}{ Pathogen } & \multirow[t]{2}{*}{ Location } & \multicolumn{2}{|c|}{$\begin{array}{l}\text { Peak mean response } \\
\text { (SFUs per million PBMCs) }\end{array}$} & \multirow[t]{2}{*}{ References } \\
\hline & & & & Arithmetic & Geometric & \\
\hline \multirow[t]{2}{*}{ Plasmid DNA } & ME-TRAP & P.falciparum & UK & 74 & 66 & 66 \\
\hline & CS protein & P.falciparum & USA & & 30 & 75 \\
\hline \multirow[t]{2}{*}{ RTS,S in ASO2 } & CS fragment & P. falciparum & UK & $50-130$ & & $\begin{array}{r}39, \\
\text { unpublished } \\
\text { observations }^{\ddagger}\end{array}$ \\
\hline & & & The Gambia & $<50$ & $<50$ & 103 \\
\hline $\begin{array}{l}\text { ICC-1132 in } \\
\text { Montanide ISA } 720\end{array}$ & CS epitopes & P.falciparum & UK & $<50$ & $<50$ & 42 \\
\hline Adenovirus Hu5 & Gag & HIV & USA & & $150-200^{\S}$ & $\begin{array}{l}\text { Unpublished } \\
\text { observations }^{\S}\end{array}$ \\
\hline \multirow[t]{2}{*}{ FP9-MVA } & ME-TRAP & P.falciparum & UK & 610 & & 9 \\
\hline & & & The Gambia & 350 & 156 & 70 \\
\hline \multirow[t]{2}{*}{ DNA-MVA } & ME-TRAP & P.falciparum & UK & 1,430 & 708 & 66 \\
\hline & & & The Gambia & 680 & 331 & 70 \\
\hline BCG-MVA & Antigen $85 \mathrm{~A}$ & $\begin{array}{l}\text { Mycobacterium } \\
\text { tuberculosis }\end{array}$ & UK & 3,248 & & 7 \\
\hline
\end{tabular}

"Peak mean response of group of all vaccinees at any time point post-vaccination, to peptides spanning the vaccine insert, as measured by an interferon- $\gamma$ enzyme-linked immunosorbent spot assay. ${ }^{\ddagger}$ S. J. Dunachie, M. Walther, J. E. Epstein, D. J. Carucci, A.V.S.H.

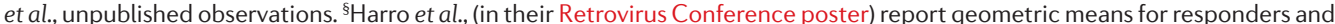
provide percentage of responders among vaccinees. The mean provided here is an estimate across all vaccinees from these data, pooling low and high vector-specific antibody groups. BCG, Mycobacterium bovis bacillus Calmette-Guérin; CS, circumsporozoite; FP9, fowlpox virus strain 9; ME, multiepitope; MVA, modified virus Ankara; PBMCs, peripheral-blood mononuclear cells; P. falciparum, Plasmodium falciparum; SFUs, spot forming units; TRAP, thrombospondin-related adhesion protein.

Using a similar assay, researchers in Kenya identified a correlation with protection against malarial anaemia and in vitro responses to a series of $\mathrm{CD}^{+} \mathrm{T}$-cell epitopes from six pre-erythrocytic antigens ${ }^{95}$. These peptides correspond almost exactly to those in the multiepitope string ${ }^{65}$ of the ME-TRAP insert in current vaccine vectors (see earlier). In contrast to these studies of cultured IFN $\gamma$ ELISPOT responses, responses to TRAP ${ }^{96}$, as well as to CS protein ${ }^{10}$ measured by ex-vivo IFN $\gamma$ ELISPOT have failed to show correlations with protection, but the levels of responses measured are generally very low and well below those that are now achievable by current vectored vaccines.

In parallel with the increased general interest in regulatory $T$ cells ${ }^{97}$, several studies have indicated that these cells have an important role in malaria. This is best defined in rodent models of blood-stage infection, in which depletion of $\mathrm{CD} 4{ }^{+} \mathrm{CD} 25^{+}$regulatory T cells protected mice from death by infection with Plasmodium yoelii $i^{98}$. Parasite strain differences in regulatory T-cell effects seem to relate to differential induction of transforming growth factor- $\beta$ (TGF $\beta$ ), with a more virulent parasite strain inducing more TGF $\beta$ and therefore more regulatory $\mathrm{T}$ cells, resulting in a weaker overall protective T-cell response $\mathrm{e}^{99}$. In human volunteers challenged with sporozoites, regulatory $\mathrm{T}$ cells also seem to influence parasite growth rates ${ }^{100}$. Some vaccines, including MVA, induce forkhead box P3 (FOXP3)-expressing regulatory T cells as well as effector T cells (H. A. Fletcher, A. A. Pathan, S. M. Keating, A.V.S.H., H. McShane, et al., unpublished observations), and depletion of regulatory
$\mathrm{T}$ cells in mice enhances vaccine immunogenicity ${ }^{101-103}$. Studies of the relevance of regulatory T-cell populations to natural malarial immunity are required.

Vaccine-induced immunity. Recently, immune correlates of protection have begun to emerge in vaccine trials (TABLE 2). Using ex vivo IFN $\gamma$ ELISPOT assays that measure both $\mathrm{CD}^{+}$and $\mathrm{CD} 8^{+} \mathrm{T}$ cells, Webster et al. ${ }^{3}$ found an overall correlation of the immunogenicity of various prime-boost immunization regimes with efficacy, as measured by delay in time to parasitaemia. However, this correlation could, in part, be explained by the higher-dose regimes also inducing stronger responses other than those measured in the ex vivo IFN $\gamma$ ELISPOT assay. However, in a recent trial of DNA-MVA vaccination with the ME-TRAP insert, responses measured by ex vivo IFN $\gamma$ ELISPOT correlated with efficacy in a single trial group of eight volunteers (S. J. Dunachie, M. Walther, J. E. Epstein, D. J. Carucci and A.V.S.H., unpublished observations). However, further analyses of these prime-boost trials have indicated that responses measured by both ex vivo and cultured IFN $\gamma$ ELISPOT assays correlated strongly with vaccine efficacy, with the cultured IFN $\gamma$ ELISPOT responses being correlated more strongly with efficacy than ex vivo IFN $\gamma$ ELISPOT responses ${ }^{74}$. Interestingly, one volunteer who was protected following three separate challenges, at 1, 6 and 20 months after vaccination with FP9-MVA encoding ME-TRAP, had persisting cultured IFN $\gamma$ ELISPOT (central memory T cell) but not ex vivo IFN $\gamma$ ELISPOT (effector T cell) responses to TRAP-derived peptides ${ }^{3}$. 
Although larger numbers of volunteers have been immunized and challenged with RTS,S/AS02A than with the anti-liver-stage vaccines, the correlates of protection are less clear with RTS,S/AS02 $\mathrm{A}^{16}$. When various trials with CS protein plus adjuvant are compared, it is evident that stronger antibody responses are associated with better protection, but this correlation has been less evident in individual trials ${ }^{16,31}$. In general, induced antibodies specific for sporozoites at titres exceeding 1 in 800 could be required for protection $^{31}$. The presence of opsonizing antibodies among a subset of vaccinees receiving RTS,S/AS02A was found to correlate with protection when total antibody titres did not ${ }^{104}$. By comparing vaccinees who were immunized with RTS,S in three different adjuvants, Sun et al. reported a correlation of cultured IFN $\gamma$ ELISPOT responses with protection, but this could in part simply reflect a greater general immunogenicity of the more protective AS02A adjuvant ${ }^{8}$. In a Phase I and subsequent Phase IIb efficacy trial of RTS,S in The Gambia $^{10,105}$, T-cell responses were weaker than in studies of non-immune individuals ${ }^{39}$ (TABLE 2), and surprisingly no correlation of efficacy with vaccine-induced antibodies or T cells was evident. In the Mozambique trials of RTS,S in children ${ }^{6}$, T-cell responses were not measured, and although antibody responses were high, they did not correlate with protection against disease. The most obvious interpretation of these data is that both a subgroup of total CS-protein-specific antibodies (perhaps mainly opsonizing antibodies) and the relatively modest T-cell responses induced by RTS,S/AS02A are relevant to protection, with the importance of each mechanism varying between individuals. Such an involvement of two protective mechanisms might account for difficulties in observing a clear correlation with either one.

If this theory is true, it indicates a possible explanation for the most puzzling and apparent finding in the RTS,S/AS02A trials: the short duration of efficacy of the vaccine. Data from sporozoite-challenge studies $^{40}$, the Gambian trial in adults ${ }^{37}$ and possibly the ongoing Mozambique trial in children ${ }^{6,106}$, indicate that much, but not all, of the efficacy of the vaccine may be lost after 2-3 months. This duration seems to be substantially different from that of most vaccines against other diseases, for which efficacy generally lasts years. Unpublished data from studies combining anti-sporozoite and anti-liver-stage vaccines in mice (C. Hutchings, A. Birkett, A. Moore and A.V.S.H., unpublished observations) show a more than additive effect of combining these two types of vaccine. So, there could also be a multiplicative interaction in humans between sporozoite-specific antibody-mediated immunity and liver-stage-specific T-cell immunity. This could simply reflect a greater ability of $\mathrm{T}$-cell responses to clear small, rather than large, numbers of infected liver cells, after a partially effective action of sporozoitespecific antibodies. This makes a strong case for including the capacity to induce both types of immunity in a malaria vaccine, and the mechanism should also affect the rate of loss of efficacy of pre-erythrocytic vaccines.
Both antibody responses and T-cell responses wane after RTS,S/AS02 immunization ${ }^{37,39}$, but if protection reflects the product of the magnitudes of two immune responses, it should wane more rapidly than either the antibody or T-cell responses. Another implication is that a small enhancement of the more labile component could significantly affect the duration of observed efficacy, as well as its initial magnitude.

\section{Combination vaccines: a faster way forward?}

Many reviews of malaria vaccines have proposed that the ultimate malaria vaccine will be multi-stage and multi-component, providing a reserve of protection in the genetically diverse human population. However, the huge array of antigens available has discouraged most investigators from assessing large mixtures of antigen without evidence in humans that individual components are protective. Also, there is increasing evidence that any immune response that is measurably protective in humans might need to be of a magnitude that is attainable by only a few approaches or vaccine types. So, it seems unlikely that any one subunit vaccine type will induce both strong T-cell responses and high levels of antibodies.

The 30\% reduction in malarial incidence achieved by RTS,S/AS02A in the recent field trial in Mozambique ${ }^{6}$ has focused attention on the possibility of supplementing this vaccine with another component to try to reach better levels of sustained efficacy ${ }^{16}$. Indeed, this has already been tried. In an unpublished study (reviewed recently ${ }^{107}$ ), the combination of RTS,S and TRAP with the AS02A adjuvant led to sterile protection after two doses in 1 out of 12 volunteers. Using TRAP alone, out of four vaccinees, none was protected. Based on earlier results with RTS,S/AS02A alone (in which six out of seven vaccinees were protected ${ }^{31}$ ), this was seen as evidence of a negative interaction between these antigens. Adding a vaccine encoding the blood-stage antigen merozoite surface protein 1, known as FMP1 to RTS,S/AS02A, but at a separate site, showed no enhancement in protection but also no evidence of reduced protection in a sporozoite-challenge study ${ }^{16}$. Other proteins that could be added to RTS,S/AS02A include LSA1 and AMA1 (REF. 16). However, antibodies specific for LSA1, which is expressed only inside hepatocytes, are unlikely to be protective, and antibodies specific for AMA1 might be parasite-variant-specific in humans, as in animals. Similarly, the short-lived CD4 ${ }^{+} \mathrm{T}$-cell responses induced by the AS02A adjuvant ${ }^{39}$ are unlikely to be of great value in this context. So, the immediate options for significantly improving RTS,S by adding other proteins in or near to clinical testing to AS02A seem, at best, high risk. Another possibility is to try to improve the adjuvant. A formulation related to AS02A, AS01B, has shown improved T-cell induction but no better protection in a pre-clinical tuberculosis vaccine $\operatorname{model}^{108}$, and it induced weaker $\mathrm{T}_{\mathrm{H}}$ 2-cell responses than $\operatorname{did} \mathrm{AS} 02 \mathrm{~A}$ in macaques $^{109}$.

Another option would be to co-administer the two vaccines that currently show most efficacy in humans: RTS,S in adjuvant and ME-TRAP in vectors. These 
vaccines have both shown good safety profiles so far in African children. This approach would involve combining strong antibody responses induced by RTS,S/AS02A against sporozoites and strong T-cell responses to TRAP that target parasitized hepatocytes. As outlined earlier, recent pre-clinical data indicate that this combination could show greater than additive protection. Although the manufacturing costs could initially be high for such a complex vaccine, if increased efficacy were observed, reducing these manufacturing costs might be easier than the continued development and testing that is required to produce a less complex but equally effective vaccine in the medium term. Furthermore, the capacity of viral vectors to accommodate large inserts, and the active development of viral vectors for other diseases such as tuberculosis ${ }^{7}$, provides possibilities for the eventual simplified administration of multi-disease vaccine combinations in the expanded programme of immunization.

\section{Better efficacy against severe malaria}

One encouraging outcome of the Mozambique RTS,S trial was the suggestion that the vaccine might work better against severe manifestations of malaria, such as cerebral malaria and severe malarial anaemia, than against uncomplicated clinical episodes ${ }^{6,110}$. However, the data are, at best, suggestive. This was not a principal trial endpoint, as the study was not designed to study severe disease. Remarkably, the annual incidence rate of severe malaria in the control group was $7 \%$, compared with the expectation of $1 \%$. In vaccinees, it was $3 \%$, indicating an efficacy of $58 \%$, but with $95 \%$ confidence intervals (of 16-81\%) overlapping the point estimate for protection against uncomplicated disease. The surprisingly high incidence of 'severe' malaria in this study $-17 \%$ of clinical cases were labelled as severe - highlights the importance of widely agreed definitions of endpoints in field trials.

Nonetheless, the interpretation might be correct because most partially effective pre-erythrocytic vaccines should probably provide more protection against severe disease than mild disease or infection. This pattern is also observed with the use of impregnated bed nets $^{111}$ and with immunogenetic risk factors ${ }^{112}$. The underlying mechanisms, although uncertain, have been debated for 10 years ${ }^{113}$ and include differential prevalences of parasites with differing virulence, and a greater likelihood of high numbers of liver-stage parasites leading to more severe malaria. Indeed, many vaccines against other diseases, for example BCG (Mycobacterium bovis bacillus Calmette-Guérin) used against tuberculosis, might provide more protection from severe disease and death than from infection or mild disease. For deployment evaluations, however, it would be useful to provide estimates, based on data, of the enhanced efficacy that the pre-erythrocytic vaccines might provide against severe malaria compared with uncomplicated malaria. This would require at least one large-scale efficacy trial to measure efficacy precisely against severe as well as uncomplicated malaria.

\section{Conclusions}

Malaria vaccines have now been shown to protect some children in field studies in Africa, the continent with the greatest malaria mortality. This has been achieved through an iterative 20-year programme of improvement of CS-protein-based vaccines that focused initially on maximizing antibody responses and more recently has involved addition of T-cell immunogenicity to yield the current RTS,S/AS02A vaccine formulation. However, the difficulty of defining an immune correlate of protection with this single-antigen vaccine highlights the challenge of identifying correlates of protection against natural infection with a parasite that has more than 5,000 genes that are expressed at specific stages in the malaria life cycle, and also illustrates that much progress can nevertheless be made in the absence of a known correlate.

An independent prime-boost approach that focuses on maximizing T-cell immunogenicity against the intracellular liver-stage parasite, using vectors expressing ME-TRAP, has generated stronger T-cell responses than any other subunit vaccine tested so far in any disease. This vaccination strategy has shown consistent partial efficacy in the human sporozoite-challenge model and, in its current FP9-MVA regime, has entered a field efficacy trial in Kenyan children. For this vaccine, T-cell immunogenicity has been shown to correlate with efficacy. The malaria field has pioneered the introduction of an adjuvant, AS02A, that is of potential value in many other diseases, and has demonstrated the feasibility of inducing sterile protection by $\mathrm{T}$ cells in the absence of antibodies.

These partial successes have been achieved by inducing potent immune responses, both antibody and $\mathrm{T}$ cells, that considerably exceed (by more than tenfold) the levels observed in residents of malaria-endemic areas. This indicates that searches for correlates of immunity in naturally exposed populations will probably miss immune-protective mechanisms that can be induced by new subunit vaccines if these high-level responses are never observed naturally.

A particular challenge facing these pre-erythrocytic vaccines is the generation of durable protection. Although both approaches can and should be improved further, it is proposed that a combination of these two existing vaccines could reach deployable levels of efficacy and durability. Several high-level initiatives from governments as well as foundations are improving the level of resources that are available for supporting malaria vaccine development, resulting in more vaccine candidates than ever before in clinical trials. A greater organizational challenge could be to bring together independent groups that are developing partially effective but potentially complementary vaccine strategies. The final goal of a highly effective multi-antigen, multi-stage, deployed malaria vaccine might require a solution to this political roadblock.

\section{Note added in proof}

Alonso et al. ${ }^{119}$ have now reported further follow-up data on the trial of RTS,S/AS02A in children from Mozambique $^{6}$ and find that efficacy from 6-18 months after vaccination is maintained at $28.9 \%$. 
McNeil, D. J. Jr., Malaria vaccine proves effective. New York Times (15 October 2004)

2. Snow, R. W., Guerra, C. A., Noor, A. M., Myint, H. Y. $\delta$ Hay, S. I. The global distribution of clinical episodes of Plasmodium falciparum malaria. Nature 434, 214-217 (2005).

3. Webster, D. P. et al. Enhanced T cell-mediated protection against malaria in human challenges by using the recombinant poxviruses FP9 and modified vaccinia virus Ankara. Proc. Natl Acad. Sci. USA 102 4836-4841 (2005).

The first report of sterile protection against malaria with vectored vaccines in a sporozoitechallenge study. One volunteer showed sterile protection that was maintained at $\mathbf{2 0}$ months after vaccination and was associated with circulating central memory $\mathrm{T}$ cells.

4. Schellenberg, D. et al. Intermittent preventive antimalarial treatment for Tanzanian infants: follow-up to age 2 years of a randomised, placebo-controlled trial. Lancet 365, 1481-1483 (2005).

5. World Health Organization. Porfolio of candidate malaria vaccines currently in development. [online], $<$ http://www.who.int/vaccine_research/documents/ malaria table.pdf $>$ (2004).

6. Alonso, P. L. et al. Efficacy of the RTS,S/AS02A vaccine against Plasmodium falciparum infection and disease in young African children: randomised controlled trial. Lancet 364, 1411-1420 (2004)

The first report of clear and significant protection against clinical malaria in African children, using the RTS,S/AS02A vaccine. Protection was observed that lasted several months against both clinical disease and parasitaemia.

7. McShane, H. et al. Recombinant modified vaccinia virus Ankara expressing antigen 85A boosts BCG-primed and naturally acquired antimycobacterial immunity in humans. Nature Med. 10, 1240-1244 (2004).

8. Sun, P. et al. Protective immunity induced with malaria vaccine, RTS,S, is linked to Plasmodium falciparum circumsporozoite protein-specific $\mathrm{CD} 4^{+}$and $\mathrm{CD} 8^{+}$ $\mathrm{T}$ cells producing IFN- $\gamma$. J. Immunol. 171, 6961-6967 (2003).

9. Vuola, J. M. et al. Differential immunogenicity of various heterologous prime-boost vaccine regimens using DNA and viral vectors in healthy volunteers. J. Immunol. 174, 449-455 (2005).

10. Reece, W. H. et al. A CD4+ T-cell immune response to a conserved epitope in the circumsporozoite protein correlates with protection from natural Plasmodium falciparum infection and disease. Nature Med. 10, 406-410 (2004)

The first evidence of a peptide-specific strong correlate of protection in a longitudinal field study using a pre-erythrocytic malaria antigen.

11. Richie, T. L. $\&$ Saul, A. Progress and challenges for malaria vaccines. Nature 415, 694-701 (2002).

12. Ballou, W. R. et al. Update on the clinical development of candidate malaria vaccines. Am. J. Trop. Med. Hyg. 71, 239-247 (2004).

13. Dunachie, S. J. \& Hill, A. V. Prime-boost strategies for malaria vaccine development. J. Exp. Biol. 206 3771-3779 (2003).

14. Moorthy, V. S., Good, M. F. \& Hill, A. V. Malaria vaccine developments. Lancet 363, 150-156 (2004).

15. Good, M. F., Stanisic, D., Xu, H., Elliott, S. \& Wykes, M. The immunological challenge to developing a vaccine to the blood stages of malaria parasites. Immunol. Rev. 201, 254-267 (2004).

16. Heppner, D. G. Jr et al. Towards an RTS, S-based, multi-stage, multi-antigen vaccine against falciparum malaria: progress at the Walter Reed Army Institute of Research. Vaccine 23, 2243-2250 (2005). A recent account of the longest-running malaria vaccine development programme.

17. Stevenson, M. M. \& Riley, E. M. Innate immunity to malaria. Nature Rev. Immunol. 4, 169-180 (2004)

18. Gupta, S. \& Day, K. P. A theoretical framework for the immunoepidemiology of Plasmodium falciparum malaria. Parasite-Immunol. 16, 361-370 (1994).

19. Nussenzweig, R. S., Vanderberg, J., Most, H. \& Orton, C. Protective immunity produced by the injection of $\mathrm{x}$-irradiated sporozoites of Plasmodium berghei. Nature 216, 160-162 (1967).

20. Clyde, D. F., Most, H., McCarthy, V. C. \& Vanderberg, J. P. Immunization of man against sporozite-induced falciparum malaria. Am. J. Med. Sci. 266, 169-177 (1973).

21. Bull, P. C. et al. Parasite antigens on the infected red cell surface are targets for naturally acquired immunity to malaria. Nature Med. 4, 358-360 (1998).
22. Dodoo, D. et al. Antibodies to variant antigens on the surfaces of infected erythrocytes are associated with protection from malaria in Ghanaian children. Infect. Immun. 69, 3713-3718 (2001).

23. Clark, I. A., al Yaman, F. M. \& Jacobson, L. S. The biological basis of malarial disease. Int. J. Parasitol. 27. 1237-1249 (1997)

24. Gardner, M. J. et al. Genome sequence of the human malaria parasite Plasmodium falciparum. Nature 419, 498-511 (2002)

25 Florens, L et al. A proteomic view of the Plasmodium falciparum life cycle. Nature 419, 520-526 (2002).

26. Hall, N. et al. A comprehensive survey of the Plasmodium life cycle by genomic, transcriptomic, and proteomic analyses. Science 307, 82-86 (2005).

27. Doolan, D. L. et al. Identification of Plasmodium falciparum antigens by antigenic analysis of genomic and proteomic data. Proc. Natl Acad. Sci. USA 100, 9952-9957 (2003).

28. Mueller, A. K et al. Plasmodium liver stage developmental arrest by depletion of a protein at the parasite-host interface. Proc. Natl Acad. Sci. USA 102 3022-3027 (2005)

29. Mueller, A. K., Labaied, M., Kappe, S. H. \& Matuschewski, K. Genetically modified Plasmodium parasites as a protective experimental malaria vaccine. Nature 433, 164-167 (2005)

30. Persson, C. et al. Cutting edge: a new tool to evaluat human pre-erythrocytic malaria vaccines: rodent parasites bearing a hybrid Plasmodium falciparum circumsporozoite protein. J. Immunol. 169 6681-6685 (2002)

31. Stoute, J. A. et al. A preliminary evaluation of a recombinant circumsporozoite protein vaccine against Plasmodium falciparum malaria. N. Engl. J. Med. 336, 86-91 (1997). The initial, highly successful, Phase I/Ila trial of the RTS,S vaccine with various adjuvants.

32. Ballou, W. R. et al. Safety and efficacy of a recombinant DNA Plasmodium falciparum sporozoite vaccine. Lancet 1, 1277-1281 (1987).

33. Herrington, D. A. et al. Safety and immunogenicity in man of a synthetic peptide malaria vaccine against Plasmodium falciparum sporozoites. Nature 328 257-259 (1987).

34. Gordon, D. M. et al. Safety, immunogenicity, and efficacy of a recombinantly produced Plasmodium falciparum circumsporozoite protein-hepatitis B surface antigen subunit vaccine. J. Infect. Dis. 171, 1576-1585 (1995).

35. Kester, K. E. et al. Efficacy of recombinan circumsporozoite protein vaccine regimens against experimental Plasmodium falciparum malaria. J. Infect. Dis. 183, 640-647 (2001).

36. Ballou, W. R. Malaria vaccines in development. Expert Opin. Emerg. Drugs 10, 489-503 (2005).

37. Bojang, K. A. et al. Efficacy of RTS,S/ASO2 malaria vaccine against Plasmodium falciparum infection in semi-immune adult men in The Gambia: a randomised trial. Lancet 358, 1927-1934 (2001).

Demonstration that the RTS,S vaccine can induce substantial protection against parasitaemia in African adults, but only for 9 weeks.

38. Alloueche, A. et al. Protective efficacy of the RTS,S/AS02 Plasmodium falciparum malaria vaccine is not strain specific. Am. J. Trop. Med. Hyg. 68, 97-101 (2003)

39. Lalvani, A. et al. Potent induction of focused $T_{4} 1$-type cellular and humoral immune responses by RTS,S/ SBAS2, a recombinant Plasmodium falciparum malaria vaccine. J. Infect. Dis. 180, 1656-1664 (1999). Quantitation of the T-cell immunogenicity of the RTS,S vaccine using IFN $\boldsymbol{\gamma}$ ELISPOT assays.

40. Stoute, J. A. et al. Long-term efficacy and immune responses following immunization with the RTS, S malaria vaccine. J. Infect. Dis. 178, 1139-1144 (1998).

41. Birkett, A. et al. A modified hepatitis B virus core particle containing multiple epitopes of the Plasmodium falciparum circumsporozoite protein provides a highly immunogenic malaria vaccine in preclinical analyses in rodent and primate hosts. Infect. Immun. 70, 6860-6870 (2002).

42. Walther, M. et al. Safety, immunogenicity and efficacy of a pre-erythrocytic malaria candidate vaccine, ICC-1132 formulated in Seppic ISA 720. Vaccine 23, 857-864 (2005).

43. Lopez, J. A. et al. A synthetic malaria vaccine elicits a potent $\mathrm{CD} 8{ }^{+}$and $\mathrm{CD} 4^{+} \mathrm{T}$ lymphocyte immune response in humans. Implications for vaccination strategies. Eur. J. Immunol. 31, 1989-1998 (2001).
44 Felnerova, D., Viret, J. F. Gluck, R. \& Moser C. Liposomes and virosomes as delivery systems for antigens, nucleic acids and drugs. Curr. Opin. Biotechnol. 15, 518-529 (2004).

45. Zurbriggen, R. Immunostimulating reconstituted influenza virosomes. Vaccine 21, 921-924 (2003)

46. Moreno, R. et al. Exploiting conformationally constrained peptidomimetics and an efficient human-compatible delivery system in synthetic vaccine design. Chembiochem. 2, 838-843 (2001).

47. Mueller, M. S. et al. Induction of parasite growthinhibitory antibodies by a virosomal formulation of a peptidomimetic of loop I from domain III of Plasmodium falciparum apical membrane antigen 1. Infect. Immun. 71, 4749-4758 (2003).

48. Schofield, L. et al. $\gamma$-Interferon, $C D 8^{+} T$ cells and antibodies required for immunity to malaria sporozoites. Nature 330, 664-666 (1987).

49. Doolan, D. L. \& Hoffman, S. L. The complexity of protective immunity against liver stage malaria. J. Immunol. 165, 1453-1462 (2000).

50. Romero, P. et al. Cloned cytotoxic T cells recognize an epitope in the circumsporozoite protein and protect against malaria. Nature 341, 323-326 (1989).

51. Khusmith, S., Sedegah, M. \& Hoffman, S. L. Complete protection against Plasmodium yoelii by adoptive transfer of a CD8 ${ }^{+}$cytotoxic T-cell clone recognizing sporozoite surface protein 2. Infect. Immun. 62, 2979-2983 (1994).

52. Hill, A. V. et al. Molecular analysis of the association of HLA-B53 and resistance to severe malaria. Nature 360, 434-439 (1992).

53. Allsopp, C. E. et al. Comparison of numerous delivery systems for the induction of cytotoxic T lymphocytes by immunization. Eur. J. Immunol. 26, 1951-1959 (1996).

54. Sedegah, M., Hedstrom, R., Hobart, P. $\delta$ Hoffman, S. L. Protection against malaria by immunization with plasmid DNA encoding circumsporozoite protein. Proc. Natl Acad. Sci. USA 91, 9866-9870 (1994).

55. Lanar, D. E. et al. Attenuated vaccinia viruscircumsporozoite protein recombinants confer protection against rodent malaria. Infect. Immun. 64, 1666-1671 (1996).

56. Rodrigues, E. G., Zavala, F., Eichinger, D., Wilson, J. M. $\&$ Tsuji, M. Single immunizing dose of recombinant adenovirus efficiently induces $\mathrm{CD} 8^{+} \mathrm{T}$ cell-mediated protective immunity against malaria. J. Immunol. 158, 1268-1274 (1997).

57. Li, S. et al. Priming with recombinant influenza virus followed by administration of recombinant vaccinia virus induces $\mathrm{CD} 8{ }^{+} \mathrm{T}$-cell-mediated protective immunity against malaria. Proc. Natl Acad. Sci. USA 90, 5214-5218 (1993)

58 Schneider, J. et al. Enhanced immunogenicity for $\mathrm{CD}^{+} \mathrm{T}$ cell induction and complete protective efficacy of malaria DNA vaccination by boosting with modified vaccinia virus Ankara. Nature Med. 4, 397-402 (1998).

59. Sedegah, M. et al. Boosting with recombinant vaccinia increases immunogenicity and protective efficacy of malaria DNA vaccine. Proc. Natl Acad. Sci. USA 95 7648-7653 (1998).

60 Gilbert, S. C. et al. Enhanced CD8 T cell immunogenicity and protective efficacy in a mouse malaria model using a recombinant adenoviral vaccin in heterologous prime-boost immunisation regimes. Vaccine 20, 1039-1045 (2002).

61. Anderson, R. J. et al. Enhanced CD8+ T cell immune responses and protection elicited against Plasmodium berghei malaria by prime-boost immunization regimens using a novel attenuated fowlpox virus. J. Immunol. 172, 3094-3100 (2004).

62. Rogers, W. O. et al. Multistage multiantigen heterologous prime-boost vaccine for Plasmodium knowlesi malaria provides partial protection in rhesus macaques. Infect. Immun. 69, 5565-5572 (2001).

63. Rogers, W. O. et al. Protection of rhesus macaques against lethal Plasmodium knowlesi malaria by a heterologous DNA priming and poxvirus boosting immunization regimen. Infect. Immun. 70 , 4329-4335 (2002).

Demonstration of the protective efficacy of heterologous prime-boost regimes against simian malaria in macaques.

64. Ockenhouse, C. F. et al. Phase I/Ila safety, immunogenicity, and efficacy trial of NYVAC-Pf7, a pox-vectored, multiantigen, multistage vaccine candidate for Plasmodium falciparum malaria. J. Infect. Dis. 177, 1664-1673 (1998). 
65. Gilbert, S. C. et al. A protein particle vaccine containing multiple malaria epitopes. Nature Biotechnol. 15, 1280-1284 (1997).

66. McConkey, S. J. et al. Enhanced T-cell immunogenicity of plasmid DNA vaccines boosted by recombinant modified vaccinia virus Ankara in humans. Nature Med. 9, 729-735 (2003).

\section{Demonstration that strong T-cell responses} can be generated by heterologous prime-boost immunization with DNA-MVA regimes in humans, and that these $T$ cells can confer some protection in the absence of antibodies.

67. Wang, R. et al. Induction of antigen-specific cytotoxic T lymphocytes in humans by a malaria DNA vaccine. Science 282, 476-480 (1998).

The first report of the immunogenicity of a plasmid DNA prophylactic vaccine in humans.

68. Moorthy, V. S. et al. Safety of DNA and modified vaccinia virus Ankara vaccines against liver stage $P$. falciparum malaria in non-immune volunteers. Vaccine 21, 1995-2002 (2003).

69. Moorthy, V. S. et al. Safety and immunogenicity of DNA/modified vaccinia virus ankara malaria vaccination in African adults. J. Infect. Dis. 188, 1239-1244 (2003).

70. Moorthy, V. et al. Phase 1 evaluation of 3 highly immunogenic prime-boost regimens, including a 12-month reboosting vaccination, for malaria vaccination in Gambian men. J. Infect. Dis. 189, 2213-2219 (2004).

71. Moorthy, V. S. et al. A randomised, double-blind controlled vaccine efficacy trial of DNA/MVA ME-TRAP against malaria infection in Gambian adults. PLOS Med. 1, e33 (2004)

72. Laidlaw, S. M. \& Skinner, M. A. Comparison of the genome sequence of FP9, an attenuated, tissue culture-adapted European strain of Fowlpox virus, with those of virulent American and European viruses J. Gen. Virol. 85, 305-322 (2004).

73. Bejon, P. et al. Calculation of liver-to-blood inocula parasite growth rates, and preerythrocytic vaccine efficacy, from serial quantitative polymerase chain reaction studies of volunteers challenged with malaria sporozoites. J. Infect. Dis. 191, 619-626 (2005).

74. Keating, S. M. et al. Durable human memory T cells quantifiable by cultured enzyme-linked immunospot assays are induced by heterologous prime-boost immunization and correlate with protection agains malaria. J. Immunol. 175, 5675-5680 (2005).

This study provides evidence that central memory $\mathrm{T}$ cells measured by cultured IFN $\gamma$ ELISPOT assays correlate better with protection than effector $\mathrm{T}$ cells measured by ex vivo IFN $\gamma$ ELISPOT assays

75. Wang, R. et al. Boosting of DNA vaccine-elicited $\gamma$-interferon responses in humans by exposure to malaria parasites. Infect. Immun. 73, 2863-2872 (2005).

76. Wang, R. et al. Induction in humans of $\mathrm{CD}^{+}$and $\mathrm{CD}^{+} \mathrm{T}$ cell and antibody responses by sequential immunization with malaria DNA and recombinan protein. J. Immunol. 172, 5561-5569 (2004).

77. Reyes-Sandoval, A. et al. Human immunodeficiency virus type 1-specific immune responses in primates upon sequential immunization with adenoviral vaccine carriers of human and simian serotypes. J. Virol. 78 , 7392-7399 (2004).

78. Farina, S. F. et al. Replication-defective vector based on a chimpanzee adenovirus. J. Virol. 75, 11603-11613 (2001).

79. Egan, J. E. et al. Efficacy of murine malaria sporozoite vaccines: implications for human vaccine development. Science 236, 453-456 (1987)

80. Zavala, F. et al. Synthetic peptide vaccine confers protection against murine malaria. J. Exp. Med. 166, 1591-1596 (1987)

81. Good, M. F. et al. Genetic control of the immune response in mice to a Plasmodium falciparum sporozoite vaccine. Widespread nonresponsiveness to single malaria $T$ epitope in highly repetitive vaccine. J. Exp. Med. 164, 655-660 (1986).

82. Charoenvit, Y. et al. CD4+ T-cell- and $\gamma$-interferondependent protection against murine malaria by immunization with linear synthetic peptides from a Plasmodium yoelii 17-kilodalton hepatocyte erythrocyte protein. Infect. Immun. 67, 5604-5614 (1999).

83. Scheller, L. F. \& Azad, A. F. Maintenance of protective immunity against malaria by persistent hepatic parasites derived from irradiated sporozoites. Proc. Natl Acad. Sci. USA 92, 4066-4068 (1995).
84. Berenzon, D et al. Protracted protection to Plasmodium berghei malaria is linked to functionally and phenotypically heterogeneous liver memory CD8 T cells. J. Immunol. 171, 2024-2034 (2003).

85. Dolo, A. et al. Epidemiology of malaria in a village of Sudanese savannah in Mali (Bancoumana). Anti-TRAP and anti-CS humoral immunity response. Bull. Soc. Pathol. Exot. 96, 287-290 (2003).

86. Scarselli, E. et al. Analysis of the human antibody response to thrombospondin-related anonymous protein of Plasmodium falciparum . Infect. Immun. 61, 3490-3495 (1993).

87. Dolo, A. et al. Thrombospondin related adhesive protein (TRAP), a potential malaria vaccine candidate. Parassitologia 41, 425-428 (1999).

88. John, C. C., Zickafoose, J. S., Sumba, P. O. King, C. L. \& Kazura, J. W. Antibodies to the Plasmodium falciparum antigens circumsporozoite protein, thrombospondin-related adhesive protein, and liver stage antigen 1 vary by ages of subjects and by season in a highland area of Kenya. Infect. Immun. 71, 4320-4325 (2003)

89. Sinigaglia, F. et al. A malaria T-cell epitope recognized in association with most mouse and human MHC class II molecules. Nature 336, 778-780 (1988).

90. Sallusto, F., Geginat, J. \& Lanzavecchia, A. Central memory and effector memory T cell subsets: function, generation, and maintenance. Annu. Rev. Immunol. 22, 745-763 (2004).

91. Flanagan, K. L. et al. Unique T cell effector functions elicited by Plasmodium falciparum epitopes in malaria-exposed Africans tested by three T cell assays. J. Immunol. 167, 4729-4737 (2001)

92. Godkin, A. J., Thomas, H. C. \& Openshaw, P. J. Evolution of epitope-specific memory $\mathrm{CD}^{+} \mathrm{T}$ cells after clearance of hepatitis $\mathrm{C}$ virus. J. Immunol. 169, 2210-2214 (2002)

93. Luty, A. J. et al. Interferon- $\gamma$ responses are associated with resistance to reinfection with Plasmodium falciparum in young African children. J. Infect. Dis. 179, 980-988 (1999).

94. John, C. C. et al. $\gamma$-Interferon responses to Plasmodium falciparum liver stage antigen 1 and thrombospondin-related adhesive protein and their relationship to age, transmission intensity, and protection against malaria. Infect. Immun. 72 5135-5142 (2004)

95. Ong'echa, J. M. et al. Association of interferon- $\gamma$ responses to pre-erythrocytic stage vaccine candidate antigens of Plasmodium falciparum in young Kenyan children with improved hemoglobin levels: XV. Asembo Bay Cohort Project. Am. J. Trop. Med. Hyg. 68, 590-597 (2003).

96. Flanagan, K. L. et al. Ex vivo interferon- $\gamma$ immune response to thrombospondin-related adhesive protein in coastal Kenyans: longevity and risk of Plasmodium falciparum infection. Am. J. Trop. Med. Hyg. 68 421-430 (2003)

97. Belkaid, Y. \& Rouse, B. T. Natural regulatory T cells in infectious disease. Nature Immunol. 6, 353-360 (2005)

98. Hisaeda, H. et al. Escape of malaria parasites from host immunity requires $\mathrm{CD} 4+\mathrm{CD} 25+$ regulatory T cells. Nature Med. 10, 29-30 (2004).

99. Omer, F. M., de Souza, J. B. \& Riley, E. M. Differential induction of TGF- $\beta$ regulates proinflammatory cytokine production and determines the outcome of lethal and nonlethal Plasmodium yoelii infections. J. Immunol. $171,5430-5436$ (2003)

100. Walther, M. et al. Upregulation of TGF- $\beta$, FOXP3 and $\mathrm{CD} 4{ }^{+} \mathrm{CD} 25^{+}$regulatory T cells correlates with more rapid parasite growth in human malaria infection. Immunity 23, 287-296 (2005)

101. Haeryfar, S. M., DiPaolo, R. J., Tscharke, D. C. Bennink, J. R. \& Yewdell, J. W. Regulatory T cells suppress $C D 8^{+} \mathrm{T}$ cell responses induced by direct priming and cross-priming and moderate mmunodominance disparities. J. Immunol. 174, 3344-3351 (2005).

102. Moore, A. C., Gallimore, A., Watkins, K. R. Gilbert, S. C. \& Hill, A. V. S. Anti-CD25 antibody enhancement of vaccine-induced immunogenicity to bacterial, viral and parasitic antigens: increased durable cellular immunity with reduced immunodominance. J. Immunol, (in the press).

103. Haeryfar, S. M. et al. Regulatory T cells suppress $\mathrm{CD}^{+} \mathrm{T}$ cell responses induced by direct priming and cross-priming and moderate immunodominance disparities. J. Immunol. 174, 3344-3351 (2005).

104. Schwenk, R. et al. Opsonization by antigen-specific antibodies as a mechanism of protective immunity induced by Plasmodium falciparum circumsporozoite protein-based vaccine. Parasite Immunol. 25, 17-25 (2003).

105. Pinder, M. et al. Cellular immunity induced by the recombinant Plasmodium falciparum malaria vaccine RTS, S/AS02, in semi-immune adults in The Gambia. Clin. Exp. Immunol. 135, 286-293 (2004).

106. Smith, P. G. \& Milligan, P. J. Malaria vaccine: 3 or 6 months' protection? Lancet 365, 472-473 (2005)

107. Heppner, D. G. et al. in New Generation Vaccines (eds Levine, M. M., Kaper J. B., Rappuoli, R. Liu, M. A. \& Good, M. F.) 851-860 (Marcel Dekker New York, 2004)

108. Skeiky, Y. A. et al. Differential immune responses and protective efficacy induced by components of a tuberculosis polyprotein vaccine, Mtb72F, delivered as naked DNA or recombinant protein. J. Immunol. 172, 7618-7628 (2004)

109. Pichyangkul, S. et al. Pre-clinical evaluation of the malaria vaccine candidate $P$. falciparum MSP1 (42) formulated with novel adjuvants or with alum. Vaccine 22, 3831-3840 (2004)

110. Alonso, P. L. et al. The effect of insecticide-treated bed nets on mortality of Gambian children. Lancet 337, 1499-1502 (1991)

111. Alonso, P. L. et al. A malaria control trial using insecticide-treated bed nets and targeted chemoprophylaxis in a rural area of The Gambia, west Africa. 6. The impact of the interventions on mortality and morbidity from malaria. Trans. R. Soc. Trop. Med. Hyg. 87 (Suppl. 2), 37-44 (1993).

112. Hill, A. V. et al. Common west African HLA antigens are associated with protection from severe malaria. Nature 352, 595-600 (1991)

113. Gupta, S. \& Hill, A. V. Dynamic interactions in malaria: host heterogeneity meets parasite polymorphism. Proc. R. Soc. Lond. B. 261, 271-277 (1995)

114. Wang, R. et al. Induction of CD4 ${ }^{+} \mathrm{T}$ cell-dependent $\mathrm{CD}^{+}$type 1 responses in humans by a malaria DNA vaccine. Proc. Natl Acad. Sci. USA 98, 10817-10822 (2001)

115. Doolan, D. L. et al. DNA vaccines for malaria: the past, the present $\bar{\alpha}$ the future. Indian. J. Med. Res. 106, 109-119 (1997).

116. Luke, T. C. \& Hoffman, S. L. Rationale and plans for developing a non-replicating, metabolically active, radiation-attenuated Plasmodium falciparum sporozoite vaccine. J. Exp. Biol. 206, 3803-3808 (2003).

117. Lawrence, G. et al. Effect of vaccination with 3 recombinant asexual-stage malaria antigens on initial growth rates of Plasmodium falciparum in nonimmune volunteers. Vaccine 18, 1925-1931 (2000)

118. Genton, B. et al. A recombinant blood-stage malaria vaccine reduces Plasmodium falciparum density and exerts selective pressure on parasite populations in a Phase $1-2 b$ trial in Papua New Guinea. J. Infect. Dis. 185, 820-827 (2002)

119. Alonso, P. L. et al. Duration of protection with RTS,S/ ASO2A malaria vaccine in prevention of Plasmodium falciparum disease in Mozambican children: singleblind extended follow-up of a randomised controlled trial. Lancet 15 November 2005 (doi:10.1016 S0140-6736(05)67669-6).

\section{Acknowledgements}

Most work in the author's laboratory is supported by the Wellcome Trust.

\section{Competing interests statement}

The author declares competing financial interests: see web version for details.

\section{DATABASES}

The following terms in this article are linked online to:

Infectious disease information:

http://www.cdc.gov/ncidod/diseases/index.htm

malaria

FURTHER INFORMATION

Adrian Hill's homepage:

http://www.well.ox.ac.uk/hill/

Malaria Vaccine Technology Roadmap:

http://wwwmalariavaccineroadmapnet

Pevion Biotech. Ltd.: http://www.pevion.com

Report of the Commission for Africa:

http://www.commissionforafrica.org

Retrovirus Conference poster:

http://www.retroconference.org/2005/CD/PDFs/504.pdf

Sanaria Inc.: http://www.sanaria.com

Access to this interactive links box is free online. 